\title{
Violência em idosos após a aprovação do Estatuto do Idoso: revisão integrativa
}

Violence in older people after the approval of the Older Adult Statute: an integrative review

Violencia en ancianos luego de la aprobación del Estatuto del Anciano: revisión integrativa

Simone Camargo Oliveira ${ }^{1}$, Alessandra Cássia Leite ${ }^{2}$, Luzia Cristina Antoniossi Monteiro ${ }^{3}$, Sofia Cristina lost Pavarini ${ }^{4}$

\begin{abstract}
RESUMO
A violência é considerada um grave problema de saúde pública e o Estatuto do Idoso é um importante instrumento para combater a violência contra o idoso. Este trabalho trata-se de uma revisão integrativa com objetivo de identificar os principais aspectos da violência física, sofrida pelo idoso após a aprovação do Estatuto do Idoso no Brasil, em 2003. A escolha por esse período baseia-se no fato da aprovação do Estatuto do Idoso ser considerada um marco legal nas políticas públicas. Foram identificados seis artigos para análise. Os resultados revelam que a família, em geral, é o agente agressor do idoso, e o ambiente doméstico é o local de maior violência, existindo consequências físicas decorrentes da violência. Os cuidados com idosos que sofreram violência englobam serviços de proteção contra violência. Concluímos que a promulgação do Estatuto do Idoso contribuiu para o aumento da consciência e informação em relação à violência contra o idoso.
\end{abstract}

Descritores: Idoso; Violência; Saúde Pública.

\section{ABSTRACT}

Violence is considered to be a serious public health problem and the Older Adult Statute is an important instrument in fighting violence against older people. This study constitutes an integrative review aimed at identifying the main factors regarding physical violence suffered by older people following approval of the Older Adult Statute in Brazil, in 2003. This period was chosen based on the fact that the approval of the Older Adult Statute is considered to be a legal milestone in public policy. Six articles were identified for analysis. Results show that the family is most often the abusive agent of the older adult, and the domestic environment is the place of greatest violence, with physical consequences resulting from this violence. Healthcare provided to older adults who have suffered from violence includes involving protective services against this type of abuse. The authors conclude that the promulgation of the Older Adult Statute contributed to the increase of awareness and information regarding violence against older people.

Descriptors: Aged; Violence; Public Health.

\section{RESUMEN}

La violencia es considerada un grave problema de salud pública; el Estatuto del Anciano es un importante instrumento para combatir la violencia contra mayores. Revisión integrativa que objetivó identificar los principales aspectos de la violencia física en ancianos luego de aprobarse el Estatuto del Anciano en Brasil, en 2003. La elección de tal período se basa en el hecho de que la aprobación del Estatuto del Anciano se considera un marco legal en las políticas públicas. Fueron identificados seis artículos para análisis. Los resultados revelan que la familia, en general, es el agente agresor del anciano, y el ámbito doméstico el lugar de mayor violencia, existiendo consecuencias físicas derivadas de la violencia. Los cuidados con ancianos que sufrieron violencia, incluyen servicios de protección contra la misma. Concluimos en que la promulgación del Estatuto del Anciano contribuyó al aumento de conciencia e información relativas a la violencia contra el anciano.

Descriptores: Anciano; Violencia; Salud Pública.

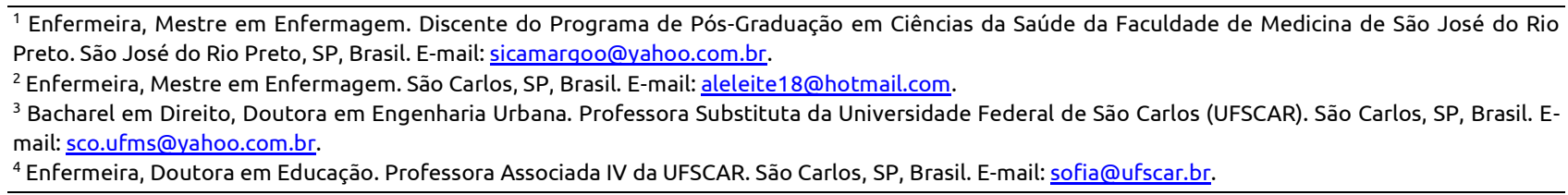




\section{INTRODUÇÃO}

Com o aumento da expectativa de vida, aumenta também a possibilidade do idoso ser acometido por várias doenças. Quando isso acontece, todo sistema familiar passa a ser comprometido. Para se prevenir isso, é importante a atenção do profissional de saúde para os sinais de sobrecarga dos cuidadores familiares que são: "distúrbios de sono, perda de energia, fadiga crônica, isolamento, uso abusivo de substâncias, fumo, problemas físicos, alteração de memória, baixa concentração, agressividade, dificuldade de concentração"(1).

A co-dependência causada pelo processo de envelhecimento pode acabar ocasionando conflitos que ocorrem no âmbito familiar, institucional e no convívio social. Nessas situações, é comum acontecer o fenômeno da violência contra o idoso(2).

O Estatuto do Idoso(3) apresenta no Art. $1^{\circ}$ que o idoso deve ser protegido e respeitado, tendo a família o dever de respaldá-lo em suas necessidades básicas, sem prejuízo de sua proteção integral. Também pontua no Art. $2^{\circ}$ que, caso o idoso seja submetido à situação de violência, as pessoas envolvidas serão punidas conforme estabelecido na Lei ou por outros meios.

Para fins desse artigo utilizaremos o conceito de violência como uma situação que pode ser produzida por pessoas, grupos, classes ou nações, que tem como objetivo prejudicar, ferir, multilar ou matar o outro(4). A Organização Mundial de Saúde(5) define a violência contra a pessoa idosa como qualquer ato, único ou repetitivo, ou omissão, que ocorra em qualquer relação supostamente de confiança, que cause dano ou incômodo a ela.

A consequência que a violência causa para a saúde do indivíduo, da sua família e da sociedade faz com que esse agravo seja considerado um problema de saúde pública com alto custo emocional e social(5).

Durante muito tempo, a família era responsabilizada pelos atos de violência contra o idoso, porém o fenômeno do envelhecimento populacional desencadeou um processo denominado como "elevação da consciência sobre os direitos dos idosos", despertando a sociedade para a questão do abuso aos idosos e aumentando a responsabilidade do estado(2).

Mais abrangente que a Política Nacional do Idoso, o Estatuto do Idoso, aprovado em setembro de 2003, institui penas severas para quem desrespeita cidadãos da terceira idade determinando que nenhum idoso poderá ser objeto de negligência, discriminação, violência, crueldade ou opressão(3).

O Relatório Mundial sobre violência, realizado pela Organização Mundial da Saúde ${ }^{(5)}$ pontua que a maior incidência de agressão ao idoso acontece no âmbito familiar, sendo que a maior contribuição para maior vulnerabilidade são os seguintes fatores: agressor vive no mesmo local que a vítima, a dependência financeira é existente entre pais e filhos, a comunicação é deficiente, falta afeto na relação e os vínculos nessas relações familiares estão se afrouxando, o idoso e a família estão se isolando.

Quando abordada violência contra a pessoa idosa, é importante a adequada atenção social na comunicação, que muitas vezes é inadequada e deficiente ${ }^{(6)}$.

Sendo assim, o presente artigo teve como objetivo realizar uma revisão integrativa de literatura com o intuito de identificar quais os principais aspectos da violência física no idoso após a aprovação do Estatuto do Idoso no Brasil.

Para alcançar tais objetivos, consideramos a importância das publicações sobre saúde coletiva nas principais bases de dados referentes à saúde, levandonos a refletir sobre as publicações científicas em relação ao idoso em situação de violência após a aprovação do Estatuto do Idoso no Brasil. Esta proposta se diferencia da revisão sistemática sobre violência em idosos realizada por Minayo, Souza e Paula ${ }^{(4)}$ por considerar como marco temporal para a pesquisa a aprovação do Estatuto do Idoso e por analisar as situações de violências físicas em idosos. Já o estudo referido(4), abordou os tipos de violências que vitimizam a população idosa e suas causas externas.

\section{DELINEAMENTO METODOLÓGICO}

Trata-se de uma revisão integrativa da literatura(7) que segue as seguintes etapas: 1) identificação da hipótese ou questão norteadora; 2) seleção da amostragem, momento de determinar os critérios de inclusão ou exclusão, oferecendo meios para proporcionar qualidade e confiabilidade na seleção; 3) categorização do estudo, com o objetivo de sumarizar e organizar tais informações; 4) análise dos dados; 5) discussão e interpretação dos resultados; e 6) apresentação da revisão integrativa e síntese do conhecimento. 
Neste estudo, a questão norteadora, "Como foi o processo de produção de conhecimento relacionado ao idoso em situação de violência após a aprovação do Estatuto do Idoso?", foi relacionada às publicações científicas sobre o idoso em situação da violência após a aprovação do Estatuto do Idoso. Essa pergunta norteou o desenvolvimento deste estudo com a finalidade de levantar informações produzidas sobre o tema e proporcionar uma síntese de conhecimento, segundo os níveis de evidências encontrados nas produções científicas. Quantos artigos foram publicados e sobre o que versavam. A escolha da avaliação dos artigos após a sua aprovação se deu pelo fato do Estatuto(3) ser considerado um importante instrumento para coibir a violência contra o idoso e ser um marco legal nas políticas públicas na área do envelhecimento no Brasil.

Foram consultadas as bases de dados: Literatura Latino-Americana e do Caribe em Ciências da Saúde LILACS e Medical Literature Analysis and Retrieval System Online - MEDLINE, focalizando apenas as publicações nacionais, no período de setembro de 2003 a setembro de 2011. Definiram-se essas bases de dados por serem as principais na área de saúde para o contexto pretendido no estudo. Determinou-se a busca nesse espaço de tempo, considerando- se que o Estatuto do Idoso foi aprovado em setembro de 2003. Acredita-se que esse período constitui um recorte temporal, em que o assunto violência contra os idosos é de grande relevância e a produção de conhecimento nesta área é esperada.

Os níveis de evidencia dos artigos foram analisados por meio dos critérios propostos por Boyle ${ }^{(8)}$. Segundo esse autor, os trabalhos podem ser divididos nas categorias A e B. A categoria A indica baixo risco de viés; os trabalhos deveriam atender pelo menos seis dos oito critérios propostos a seguir: 1) estudos que utilizam amostra representativa da população em geral; 2) público-alvo claramente definido; 3) entrevistados que tenham características correspondentes à populaçãoalvo; 4) métodos de avaliação padronizados; 5) instrumentos que apresentem confiabilidade; 6) instrumentos validados; 7) análise estatística descrita; 8) intervalo de confiança adequado. Artigos classificados na categoria $B$ atendem até quatro dos itens, apresentando risco de viés moderado.

Assim como critério de inclusão, além das bases citadas, o artigo deveria ser nacional, pois trata-se do
Estatuto do Idoso no Brasil; possuir texto completo disponível publicamente e ser publicado no idioma português, inglês ou espanhol e pertencer a categoria $A$ de acordo com as categorias propostas por Boyle(8). Foram utilizados os Descritores em Ciências da Saúde (DeCS): idoso, violência e saúde pública, sendo que esta mesma sequência foi utilizada para a busca nas bases de dados não sendo realizado agrupamento de descritores. O descritor saúde pública foi utilizado pelo fato de as consequências que a violência causa para a saúde do indivíduo, da sua família e da sociedade, determinarem que esse agravo seja considerado um problema de saúde pública.

A revisão nas bases de dados resultou em 64 publicações, sendo 43 na MEDLINE, 21 na LILACS. Dois artigos, idênticos, foram encontrados em duas bases de dados distintas, sendo então considerados apenas uma vez. Destes, 24 possuíam o texto completo disponível publicamente. Após cuidadosa leitura 18 artigos foram excluídos por não corresponderem à temática proposta, especificamente por não abordarem a questão da violência física contra o idoso em sua temática e por serem estudos que não apresentaram os descritores de forma vinculada. Assim, foram selecionados seis artigos para a análise, todos pertencentes a categoria $A$ de acordo com a teoria de Boyle $e^{(8)}$.

Para a organização e tabulação dos dados, as pesquisadoras elaboraram instrumento de coleta de dados contendo as seguintes informações: caracterização do título, procedência, autores, periódico (volume, número, página, ano), local do estudo e tipo de estudo, objetivos e principais resultados.

Posteriormente, foram extraídos os principais conceitos abordados em cada artigo e que correlacionavam com o objetivo do estudo. Após, os trabalhos foram comparados e agrupados por similaridade de conteúdo, sob a forma de categorias buscando evidenciar as questões mais relevantes, sendo construídas quatro categorias para análise, assim especificadas: perfil dos agressores dos idosos; local de maior ocorrência de violência contra os idosos; consequências da agressão e rede intersetorial de denúncia a que o idoso pode recorrer em caso de violência. 
APRESENTAÇÃO E DISCUSSÃO DOS RESULTADOS

As publicações analisadas são datadas de 2003 a 2011 , sendo $16,7 \%$ em $2010,33,3 \%$ em $2008,16,7 \%$ em 2007, 16,7 em 2006 e 16,7\% em 2003. Dois artigos foram publicados no Ceará e no Rio de Janeiro, um em Pernambuco e um em São Paulo. Houve predomínio das publicações na região nordeste. Dos estudos analisados, cinco foram publicados no idioma português e um na língua inglesa. A respeito de delineamento metodológico, dois estudos (50\%) correspondem a uma análise documental retrospectiva, dois (33\%) utilizam abordagem quantitativa e um estudo, (17\%) análise qualitativa. Considerando-se a formação acadêmica dos autores, três artigos foram escritos por enfermeiras e dois por médicos (Quadro 1). 
Quadro 1: Publicações científicas encontradas nas bases de dados LILACS e MEDLINE sobre a produção científica com relação a violência em idosos no período de setembro de 2003 a setembro de 2011, segundo a caracterização do título, procedência, autores, periódico (volume, número, página, ano), local do estudo e tipo de estudo, objetivos e

\begin{tabular}{|c|c|c|c|c|}
\hline Autores do Artigo/Título & $\begin{array}{l}\text { Periódico (ano } \\
\text { da publicação) / } \\
\text { base de dados }\end{array}$ & Tipo de estudo & Objetivos & Principais resultados \\
\hline $\begin{array}{l}\text { Moraes CL, Júnior PCA, Reichenheim ME. } \\
\text { Rompendo o silêncio e suas barreiras: um } \\
\text { inquérito domiciliar sobre a violência } \\
\text { doméstica contra idosos em área de } \\
\text { abrangência do Programa Médico de Família } \\
\text { de Niterói, Rio de Janeiro, Brasil }\end{array}$ & $\begin{array}{l}\text { Cad. Saúde } \\
\text { Pública (2008) / } \\
\text { MEDLINE }\end{array}$ & $\begin{array}{l}\text { Estudo } \\
\text { transversal } \\
\text { populacional }\end{array}$ & $\begin{array}{c}\text { Estimar a prevalência da violência física contra } \\
\text { o idoso no ambiente doméstico em uma } \\
\text { população de baixa/média renda assistida pelo } \\
\text { Programa Médico de Família na cidade de } \\
\text { Niterói, Rio de Janeiro, Brasil }\end{array}$ & $\begin{array}{l}\text { Pontuam a necessidade da Estratégia Saúde } \\
\text { da Família incorporar em suas ações o } \\
\text { enfrentamento da violência física contra } \\
\text { idosos às suas atividades de rotinas. }\end{array}$ \\
\hline $\begin{array}{l}\text { Souza JAV, Freitas MC, Queiroz TA. Violência } \\
\text { contra os idosos: análise documental }\end{array}$ & $\begin{array}{l}\text { Rev Bras Enferm, } \\
\text { (2007) / MEDLINE }\end{array}$ & $\begin{array}{c}\text { Análise } \\
\text { documental } \\
\text { retrospectivo }\end{array}$ & $\begin{array}{c}\text { Analisar os dados de violência e maus-tratos } \\
\text { contra os idosos por meio de documentos } \\
\text { oficiais, em Fortaleza-CE }\end{array}$ & $\begin{array}{l}\text { Serviços voltados à violência e as políticas } \\
\text { públicas devem estar voltadas para papel } \\
\text { social do idoso }\end{array}$ \\
\hline $\begin{array}{c}\text { Minayo MCS, Souza ER, Paula DR. Revisão } \\
\text { sistemática da produção acadêmica brasileira } \\
\text { sobre causas externas e violências contra a } \\
\text { pessoa idosa. }\end{array}$ & $\begin{array}{l}\text { Ciência e Saúde } \\
\text { Coletiva (2010) / } \\
\text { LILACS }\end{array}$ & $\begin{array}{l}\text { Revisão } \\
\text { Sistemática }\end{array}$ & $\begin{array}{l}\text { Revisão sistemática sobre violência contra a } \\
\text { pessoa idosa no período de } 2000 \text { a } 2009 .\end{array}$ & $\begin{array}{c}\text { Salienta o aumento da produção e } \\
\text { aprimoramento metodológico nas áreas de } \\
\text { saúde pública e na formulação de políticas e } \\
\text { planos de ação. }\end{array}$ \\
\hline $\begin{array}{l}\text { Gaiolli CCLO, Rodrigues RAP. Occurrence of } \\
\text { domestic elder abuse }\end{array}$ & $\begin{array}{l}\text { Rev. Latino-am } \\
\text { Enfermagem } \\
(2008) \text { / LILACS }\end{array}$ & $\begin{array}{l}\text { Análise } \\
\text { documental } \\
\text { retrospectivo }\end{array}$ & $\begin{array}{l}\text { Verificar a ocorrência de maus-tratos } \\
\text { praticados nos domicílios contra idosos, de } \\
\text { ambos os sexos, no ano } 2006 \text {. }\end{array}$ & $\begin{array}{c}\text { Os maus-tratos no domicílio ocorreram com } \\
\text { maior frequência entre idosos do sexo } \\
\text { masculino seus agressores são filhos, netos, } \\
\text { genros e noras. A maior incidência de trauma } \\
\text { foi de ombro e braço. } \\
\end{array}$ \\
\hline $\begin{array}{c}\text { Freitas CASL, Teófilo TJS. Avaliação } \\
\text { construtivista sob uma abordagem } \\
\text { integradora e intersetorial, das ações do } \\
\text { Projeto Disque Idoso em Sobral (CE, Brasil). }\end{array}$ & $\begin{array}{l}\text { Ciência \& Saúde } \\
\text { Coletiva (2010)/ } \\
\text { LILACS }\end{array}$ & $\begin{array}{l}\text { Qualitativo } \\
\text { (grupo focal) }\end{array}$ & $\begin{array}{l}\text { Avaliar construtivistamente o Projeto Disque } \\
\text { Idoso em Sobral (Ceará) }\end{array}$ & $\begin{array}{c}\text { Os profissionais que atuam na sede do } \\
\text { projeto demonstram receio em divulgar seu } \\
\text { trabalho e acreditam que a eficácia de suas } \\
\text { ações é limitada pela falta de transporte fixo } \\
\text { e pela falta de outros profissionais } \\
\text { qualificados. }\end{array}$ \\
\hline $\begin{array}{c}\text { Melo VL, Cunha JOC, Neto GHF. Maus-tratos } \\
\text { contra idosos no município de Camaragibe, } \\
\text { Pernambuco. }\end{array}$ & $\begin{array}{l}\text { Rev. Bras. Saúde } \\
\text { Matern. Infant. } \\
\text { (2006) / LILACS }\end{array}$ & $\begin{array}{l}\text { Estudo } \\
\text { descritivo de } \\
\text { coorte } \\
\text { transversal }\end{array}$ & $\begin{array}{l}\text { Descrever a situação de maus-tratos contra } \\
\text { idosos no município de Camaragibe, na região } \\
\text { Metropolitana do Recife, Pernambuco. }\end{array}$ & $\begin{array}{l}\text { Os idosos (21\%) referiram maus-tratos, } \\
\text { embora nenhum soubesse a que órgão } \\
\text { denunciar, considerando que a comunidade } \\
\text { não tomaria atitude alguma caso ficasse } \\
\text { ciente de um caso maus-tratos contra idosos. }\end{array}$ \\
\hline
\end{tabular}


A análise dos artigos possibilitou a elaboração de quatro categorias: perfil dos agressores dos idosos; local de maior ocorrência de violência em idosos; consequências da agressão e rede intersetorial de denúncia que o idoso pode recorrer em caso de violência.

\section{Perfil dos agressores dos idosos}

A análise dos artigos mostrou que os principais perpetradores dos maus tratos contra os idosos são seus familiares, vizinhos, desconhecidos e outros ${ }^{(9-11)}$.

Um dos estudos analisados(9) afirma que o declínio da capacidade cognitiva e física do idoso, que acaba gerando maior dependência, também é considerado como um fator de risco para a violência, pois tal condição exige cuidados específicos por parte de seus cuidadores, que por sua vez, se sentem sobrecarregados ${ }^{(9)}$. Explicando o fato de os casos de maus tratos envolverem frequentemente mais idosos dependentes do que independentes, o estudo afirma que o alto índice de agressores dentro das famílias é decorrente do enfraquecimento do vínculo de solidariedade e afetividade entre seus membros, sendo, a sobrecarga do cuidador, a situação desencadeante desses abusos ${ }^{(9)}$. Este estudo também ressalta que grau de dependência entre cuidado e cuidador é um dos fatores mais importantes para ocorrência da violência doméstica, sendo essa dependência a situação que impõe a "lei do silêncio" ao indivíduo em situação de violência( ${ }^{(9)}$. Já outra investigação(10) mostrou que os filhos são os principais perpetradores dos maus tratos. Esses dados também estão de acordo com o estudo que analisou a violência contra o idoso em um município de Pernambuco, no qual os principais perpetradores dos maus-tratos do município foram: familiares, em 46 $(69,8 \%)$ ocasiões; vizinhos, em oito (12,1\%); desconhecidos, em cinco (7,6\%); e outros em quatro (6\%) casos.

A inexistência de estudos que abordem a violência contra idosos no âmbito das instituições, abrigos e hospitais é percebida negativamente pelos autores dos artigos, pois impede a compreensão dos significados e sentidos que permeiam a relação agressor-agredido e a percepção social deste fenômeno(9-11).

A literatura aponta que a maioria dos casos dessa violência é cometida por familiares, principalmente, os filhos que residem na mesma casa do idoso, com possível caso de abuso de álcool ou outras drogas ${ }^{(6)}$. É importante destacar que o abuso de álcool ou outras drogas é um fator agravante para a ocorrência da violência, pois, segundo esse mesmo autor, a embriaguez patológica é que faz com que o indivíduo manifeste sua agressividade ${ }^{(6)}$.

Ao discorrer sobre o perfil dos agressores no contexto familiar, as publicações trouxeram colaborações expressivas, como a importância de serviços e programas que possam oferecer maior suporte à família brasileira para cuidar dos idosos em seus lares, podendo ser um importante trunfo no combate à violência contra os idosos.

\section{Local de maior ocorrência de violência em idosos}

Os estudos analisados evidenciaram o ambiente doméstico como local de maior acometimento de violência contra os idosos e destacam a família como o principal responsável pelo bem estar do idoso(4,11-12).

Sabe-se que a violência pode ser identificada em espaços públicos, privados, familiares, nas relações grupais, institucionais ou interpessoais(6). Um dos estudos analisados afirma que as condições de vida devem ser consideradas como um fator de risco para a violência, pois são apontadas como possíveis causas de conflitos familiares. Essa situação se torna mais indubitável, quando a aglomeração e a falta de privacidade se tornam presentes ${ }^{(12)}$. Outro fator que merece atenção neste estudo é a questão financeira familiar, considerada como uma das principais causas da violência contra idosos no âmbito domiciliar. Tanto o idoso sustentado por seu cuidador, quanto um cuidador financeiramente dependente do idoso constituem situações de risco(12). Em geral, a agressão é conduzida por meio da expulsão do idoso do seu espaço físico e social ou por seu confinamento em espaços ínfimos na residência que the pertencem por direito(12).

Um estudo(11) aponta a contradição de que os familiares que deveriam oferecer aos idosos segurança e estabilidade necessária para o seu enfrentamento das atividades de vida diária, são os mesmos indivíduos que usurpam seus bens materiais sem o seu consentimento, privando-o de seu direito de prover de uma qualidade de vida com oportunidades e facilidades.

Idosos e familiares precisam repensar valores e comportamentos objetivando um relacionamento intergeracional mais adequado, para que o domicílio seja 
um espaço de melhor convivência familiar e com menos violência. Além disso, julga-se necessária a implementação de medidas educativas e de mobilização social, a fim de assegurar e esclarecer os direitos dos idosos e, principalmente, de auxiliar a família em seu papel de cuidador.

\section{Consequências da agressão}

Os estudos analisados apontaram as consequências físicas na violência contra idosos, muito mais do que as consequências emocionais ou financeiras ${ }^{(11-13)}$.

Um estudo ${ }^{(12)}$ que analisou a ocorrência de maus tratos praticados no domicílio contra 60 idosos de ambos os sexos, por meio da análise de laudos de exames do corpo de delito, demonstrou que o tipo mais recorrente de ferimento foram as lesões superficiais em ombros e braços, responsáveis pelo óbito de dois dos idosos. Outro dado relevante foi a constatação de que a maioria dos idosos não procurou assistência médica para os maus tratos sofridos. Outra pesquisa ${ }^{(12)}$ revela que a violência, além de prejudicar a convivência harmoniosa entre os familiares, provoca o adoecimento. Diante desse quadro é fundamental que a sociedade, como um todo, preste mais atenção à pessoa idosa, elaborando alternativas com o fim de erradicar as causas das diversas violências que este contingente populacional sofre e evitar as consequências da agressão(11).

Na publicação realizada pelo Ministério da Saúde ${ }^{(14)}$, a violência acometida contra o indivíduo idoso é considerada uma violação aos direitos humanos, consistindo em uma das causas mais relevantes de lesões, doenças, perda da produtividade, isolamento e desesperança. Entretanto, as informações sobre doenças, lesões e traumas provocadas por ações violentas contra os idosos ainda são raras no Brasil, fato também observado na literatura internacional(15).

\section{Rede intersetorial de denúncia que o idoso pode recorrer em caso de violência}

Apenas um artigo foi encontrado sobre as redes intersetoriais de denúncia em caso de violência contra o idoso. Trata-se de um estudo(13) que objetivou avaliar construtivistamente o Projeto Disque Idoso em Sobral (Ceará). Este projeto tem suas ações voltadas para a problemática, seja por agressão física, psicológica, verbal, de caráter financeiro, por abandono ou cárcere privado, ou, ainda, por negligência ${ }^{(13)}$. Observa-se que o projeto funciona a partir de denúncias que são recebidas por telefonema ou por meio de visitas ao serviço; cadastradas com detalhes; se necessário, são averiguadas por meio de uma visita domiciliar ou institucional(13). Em relação ao trabalho realizado pelo projeto, foi observado uma ausência de consenso ente os atores do Projeto Disque Idoso: para uns, o Disque Idoso tem caráter preventivo; para outros, ele é responsável apenas pelo recebimento e encaminhamento das denúncias. No entanto, a publicação apresenta o projeto "Disque Idoso" como uma eficaz rede social de combate a essa violência, sendo necessário investimento de apoio técnico e financeiro por parte da sociedade e do estado a fim de fortalecer esse serviço.

Na Assembléia Mundial de Saúde a violência foi caracterizada um problema de saúde pública mundial, tendo em vista suas graves consequências a curto e longo prazo para indivíduos, famílias, comunidades e países, além do aumento da demanda por serviços de saúde em todo mundo(12).

Nessa perspectiva, este estudo toma como contexto a necessidade da implementação de medidas educativas e da mobilização social com o objetivo de esclarecer aos idosos os seus direitos, orientar quanto à atitude apropriada a adotar diante da agressão, facilitar a denúncia e a obtenção de apoio ou ajuda, buscar junto à sociedade uma sensibilização para o problema e sua participação na construção de uma rede de proteção ao idoso(12). Para que essa mobilização social se torne realidade é essencial que ocorram mudanças públicas com relação à coleta de dados, normatização das resposta legislativas, aumento de financiamento para redes sociais que atuam no combate a esse tipo de violência, entre outros fatores ${ }^{(15)}$.

Uma pesquisa ${ }^{(10)}$ revela que $72 \%$ das denúncias de casos de violência contra idosos foram feitas por meio do programa Alô-Idoso e 118 (29\%) feitas diretamente na sede dele, sendo um número considerável de atendimentos a cada ano de atuação desse programa, demonstrando a sua importância na preservação dos direitos dos idosos, na sua reinserção na sociedade e na prevenção da sua integridade física e emocional.

Quando se trata de cuidados oferecidos aos idosos que sofreram agressão, é de suma importância a presença de profissionais qualificados, para que o cuidado e a proteção de pessoas pertencentes a essa 
faixa etária sejam realmente eficazes ${ }^{(12)}$. Destaca-se ainda o valor dos profissionais da Estratégia da Saúde da Família (ESF) na busca de uma comunicação efetiva com o idoso(9).

Os agentes comunitários de saúde apresentam um papel primordial, pois eles podem favorecer a identificação dos idosos em situação de violência, nas visitas domiciliares. A inclusão dos familiares e dos cuidadores nas ações dos agentes comunitários é fundamental, pois essas pessoas serão os facilitadores do processo( ${ }^{(9)}$. A atenção à violência contra os idosos deve visar políticas públicas que redefinam, de forma positiva, o lugar do idoso na sociedade e privilegiem o cuidado, a proteção e sua subjetividade, tanto com suas famílias como nas instituições, tanto nos espaços públicos como no âmbito privado ${ }^{(4,16)}$.

\section{CONCLUSÃO}

Durante a análise dos artigos que foram incluídos nessa revisão integrativa de literatura, pode ser observada a situação do idoso em relação à violência após a aprovação do Estatuto do Idoso.

Com a análise dos artigos, observamos que os principais perpetradores dos maus tratos contra os idosos são seus familiares e que o local de maior ocorrência de violência contra o idoso é o ambiente doméstico. A consequência física foi considerada prevalente e uma das principais consequências da violência contra o idoso. O tipo mais recorrente da violência física foram as lesões superficiais em ombros e braços. Outro dado relevante foi o da constatação de que as maiorias dos idosos não procuraram assistência médica para os maus tratos sofridos. O programa social específico contra violência analisado neste estudo o "Disque Idoso" foi considerado pelos autores como uma eficaz rede social de combate a essa violência, pois os mesmos acreditam que este grande problema social deve ser trabalhado de forma coletiva.

Observa-se por meio dos estudos analisados que o Estatuto do Idoso proporcionou nas unidades de saúde, sociais e familiares, uma maior consciência e informação em relação à violência contra o idoso. Contudo, é importante descrever que existem limitações com relação ao Estatuto do Idoso, por se tratar de um instrumento que historicamente tem pouco tempo de existência na legislação brasileira.

Os pesquisadores são enfáticos em defender a importância da elaboração de estudos pertinentes para a prevenção da violência nesses contextos e a importância da mudança nas práticas de saúde. Mesmo percebendo movimentos em diversas áreas no combate à violência contra os idosos, incluindo o Estatuto do Idoso, a produção de conhecimento nesta área deve avançar, especialmente, no que se refere às possibilidades de intervenções capazes de prevenir as causas e as consequências dessa violência.

As limitações do estudo decorrem, principalmente, pela restrição dos achados o que compromete sua generalização. Embora o tema seja bastante debatido e divulgado na mídia, nota-se a presença de informações produzidas em estudos com limitações metodológicas, o que compromete as evidencias para balizar boas práticas de atenção à saúde do idoso.

8. Boyle MH. Guidelines for evaluating prevalence studies. Evidence Based Mental Health. 1998;(1):37-39.

9. Moraes $C L$, Júnior $P C$, Areichenheim ME. Rompendo o silêncio e suas barreiras: um inquérito domiciliar sobre a violência doméstica contra idosos em área de abrangência do Programa Médico de Família de Niterói, Rio de Janeiro, Brasil. Cad. Saúde Pública. 2008;24(10):2289-2300.

10. Souza JAV, Freitas MC, Queiroz TA. Violência contra os idosos: análise documental. Rev. Brasileira de Enfermagem. 2007;60(3):26872.

11. Melo VL, Cunha JOC, Neto GHF. Maus-tratos contra idosos no município de Camaragibe, Pernambuco. Rev. Bras. Saúde Matern. Infant. 2006;(6 Supl 1):43-48.

12. Gaioli CCLO, Rodrigues RAP. A ocorrência de maus tratos doméstico em idoso. Revista Latino Americana de Enfermagem. 2008;16(3):465-70.

13. Freitas CASL, Teófilo, TJS. Avaliação construtivista sob uma abordagem integradora e intersetorial, das ações do Projeto Disque Idoso em Sobral (CE, Brasil). Ciência \& Saúde Coletiva.

2010;15(6):2825-2833. 
14. Secretaria Municipal de Saúde. Caderno de Violência contra a pessoa idosa. São Paulo (Brasil): Secretaria Municipal de Saúde, 2007.65 p.

15. Jorgest G, Daly JM, Brinig MF, Dawson JD, Schmuch GA, Ingram JG. Domestic elder abuse and the law. American Journal of Public Health. 2003;93(12):2131-2136.

16. Minayo MCS. Violência contra idosos: relevância para um velho problema. Cad. Saúde Pública. 2003;19(3):783-91.

Artigo recebido em 09/01/2011.

Aprovado para publicação em 11/06/2012.

Artigo publicado em 31/12/2012. 